\title{
Animals, handicapped children and the tragedy of marginal cases
}

\author{
James Lindemann Nelson St fohn's University, Collegeville, Minnesota, USA
}

\section{Author's abstract}

There are human beings whose psychological capacities are rivalled or exceeded by many non-human animals; such humans are often referred to as 'marginal cases'. $R G$ Frey has argued that there is no secure, non-arbitrary way of morally distinguishing between marginal humans and non-human animals. Hence, if the benefits of vivisection justify such painful and lethal procedures being performed on animals, so is the vivisection of marginal humans justified. This is a conclusion Frey is driven to with 'great reluctance', but which he can see no way to avoid. This paper points out a feature of the condition of marginal humans unnoticed by Frey and his critics: such humans have suffered a tragic harm. It points towards an analysis of this harm, in terms of counterfactuals holding for marginal humans but not for psychologically equivalent animals. Finally, it discusses the moral implications of the harm that such humans have suffered, and argues that it serves as the basis of a defence for preferring humans to non-humans in cases of morally inescapable conflict.

In recent writings - including his contribution to a symposium on vivisection, morals and medicine in this journal - R G Frey has argued that the species to which an individual belongs is not, in itself, of any moral relevance. Such a view is of continuing interest, especially in the light of current trends concerning the use of anencephalic humans as organ donors. Frey's own focus has been on humans as research models rather than therapeutic resources, but consideration of the moral importance of being human will probably have implications that go beyond the specific target of his remarks.

The conclusion he has reluctantly drawn is that if vivisection is justified by the benefits it confers, then at least some such experimentation should be done upon humans. For it would seem that, at least in many cases, we could be more confident that hoped-for benefits would be forthcoming from research employing human rather than animal models. As Frey put it:

\section{Key words}

Animal experimentation; vivisection; human experimentation. '...if securing the benefit licenses (painful) experiments on animals, it equally licenses (painful) $\vec{A}$ experiments on humans, since the benefit may be secured by either means. Moreover, we must not forget $\vec{A}$ that we have already a powerful reason for human $\stackrel{\oplus}{\oplus}$ experiments: we typically experiment upon animals $ᄋ$ with an eye toward benefiting humans, and it seems only sensible, if we want to find out the effect of some substance upon humans, that we test it upon humans. This is especially true, as doubts increasingly arise about whether extrapolations from the animal to the $\mathbb{\Phi}$ human case are not very prone to error and to the effects of in-built differences between animals ang $\varnothing_{\infty}$ humans '(1).

This conclusion is surprisingly difficult to resist. For it is morally legitimate to subject non-human animals to painful, lethal research in order to reap therapeutic benefits, but not legitimate to so treat humans, there $\stackrel{\Phi}{\Omega}$ must be some moral disanalogy between the cases. But $\overrightarrow{\vec{P}}$ for those humans psychologically on a par with non- $\frac{3}{3}$ humans - sometimes referred to in the philosophical literature as 'marginal cases' - this is hard to show. In the absence of religious grounds for valuing human life per se more highly than animal life (a possibility Frey $\underset{\oplus}{\overparen{D}}$ explicitly forswears on his own behalf and one $\bar{\sigma}$ generally problematic in a pluralistic society) the greater value of human over animal life must lie in the $ᄋ$ greater complexity of those lives, in the manifold $₹$ possibilities of enrichment they contain. But some? humans fail to enjoy such complexities. So, if the $>$ resulting benefits allow us to engage in painful experiments upon animals, then they must also allow us to engage in such experiments upon 'marginal' $O$ ) humans.

This will surely strike many as a repugnant conclusion, and Frey himself is drawn to it only hesitantly. Many writers - including Frey - haveco attempted to discover a morally significant disanalogy $\overparen{\varnothing}$ between non-human animals and marginal humans? which would justify the different status we intuitively $\square$ ascribe to them (2); others have argued that the lack of ${ }_{\vec{D}}$ any such disanalogy, far from making it permissible to

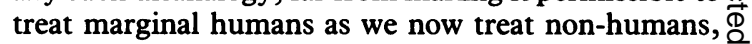
indicates that it is our practice with animals that must $\bar{\sigma}$ be altered; we must treat them as we now do marginal 
humans, ascribing to them the same rights to life, respectful treatment, and freedom from the infliction of non-trivial pain (3). In my view, however, the years following the publication of Frey's article have seen no successful response to his call for a criterion that would morally distinguish between non-humans and marginal humans.

I wish to point out a neglected distinction between 'marginal' humans and ordinary non-humans which justifies at least a minimal moral difference between them. The distinction is this: the birth of a 'marginal' human, or the reduction of a normal human to a marginal state, is a tragedy; the birth of, say, a healthy collie pup, whose potentials are roughly on a par with the human's, is not. Instances of the first sort are causes of deep grief, and not simply for ourselves. We pity the child, or the victim, the subject of this profound injury. That we do have such a reaction is, it seems to me, quite clear. How to analyze this fact, and what implications it may have for the moral status of marginal humans and non-humans, is less clear.

\section{Marginality as a harm}

One problem concerns the nature of the harm suffered by the marginal human. Consider the birth of a severely retarded child. If we are right in regarding the child's circumstance as a tragedy for the child, and not simply for others - for example the family, and all of us who cannot look on without grief - it seems that we're committed to regarding as a harm something which does not make the child worse off. For, at least in many circumstances, if the child's problem is due to its fundamental genetic constitution, it is arguable that that very child would not have existed had that genetic constitution been normal. So, it would seem that the harm we are responding to in marking the child's circumstance as tragic is not so much its affliction, but its very existence. If its retardation is a harm to it, then its existence is a harm to it, and that is a kind of harm which does not make its subject worse off than it otherwise would be.

Now, perhaps this is a bullet we simply have to bite. Thomas Nagel's work (4) suggests that there are many things that do not make us worse off - death, for instance, or calumny that we remain ignorant of, and which does not affect the attitudes or practices of others - which are yet properly seen as harms to us. Perhaps being born with defects that are intimately related to one's most basic causally significant structure is just another of them. But there is at least one other way of thinking about the matter. Even if one's genetic structure is a necessary fact about one, and even if, as some philosophers hold (5), the causal properties of that structure are necessary as well, so that there is no possible world where this child exists either with a different genetic structure, or with the same genetic structure but with different properties - it is still the case that intervention in the expression of that structure's properties is possible (6). So the content of the tragedy we lament in contemplating the existence of a massively defective child may be the following: things could be otherwise for this very child. Contemplating the birth of, for example, a healthy Wistar rat evokes no such sense of tragedy (if we focus simply on the animal itself, and not on, say, its impending fate at the hands of human beings). The rat could not be the possessor of traits that would allow it the form of life held by paradigm humans and still be the same rat, or perhaps even a rat at all; such a radical alteration of its genetic structure would constitute an essential, numerical change in its identity.

If the foregoing analysis of the presuppositions behind our differential response to the birth of a massively damaged human and the birth of a healthy rat seems inaccurate, or simply too metaphysical, other, simpler analyses can be offered. We may merely be responding to the fact that the damaged child will never enjoy the kind of life that it might have, had it not been so badly damaged, or if the damages were able to be corrected. The normal non-human's abilities to fully participate in its form of life, to enjoy whatever good is there to be gotten, is intact and there is nothing to mourn in that fact (7).

\section{Moral implications of the harm}

Whatever the correct account of the metaphysical underpinnings of the matter, intuitively it seems clear that a marginal human being has suffered a massive harm. A healthy animal, despite its psychological parity with the marginal human, has not. How morally significant is this contrast?

Consider that the marginal human's situation calls forth our compassion, and our pity, and that there is something wanting in the character of those who are not so moved by this tragedy. But not every kind of behaviour is compatible with feeling compassion for something; it seems queer, to say the least, that one should pity someone, and then add to the burdens of the object of pity. Those who are alive to the tragedy of marginal cases will respond by acting to ameliorate such a human's condition; surely they will not exacerbate that individual's suffering, unless under great need. Those who are not alive to that suffering are people who have lost a crucial sympathy.

Those who defend subjecting marginal humans to the same kind of treatment currently suffered by animals, such as Frey, could well reply that sensitivity to the tragedy will not itself rule out the possible use of marginal humans in painful experimentation, and I suppose this has to be granted. But it does suggest that whatever need might drive us to such procedures would have to be greater than that which would justify such suffering inflicted on animals. However, this general point seems to me to leave altogether open the question of what kind of need would be adequate to justify different types of experimentation upon animals; I will briefly return to this claim later.

First, I want to consider some possible replies to my reading of what the tragedy of marginal cases implies for our behaviour. It might be said, for instance, that whether a given potential experimental subject has or 
has not undergone a tragedy makes no difference to its entitlements. It has no rights against me that are not possessed by more fortunate members of its class - at least, if I am not the cause of its tragedy.

This line can be rebutted from both consequential and non-consequential perspectives. Considerations of justice in the distribution of burdens, for example, should constrain us from further afflicting the already afflicted, where at all possible. And, from a more utilitarian view, although we may have to concede that experimenting on a human might carry no greater cost for the resultant value than would similar procedures on an animal, there remains the impact on moral discernment and sensitivity, on compassion and pity, which are themselves dispositions to be encouraged because they are sources of utility.

It might also be argued that the position defended here begs the question, since it appeals to emotional reactions (grief, pity, compassion, etc) which it assumes to be justifiably occasioned by the situation of marginal humans, but not by the situation of animals. But feelings of pity and compassion, and so forth, are not constitutive of tragedy; there surely are unmarked, unmourned tragedies. To be a subject of a tragedy is to be the subject of a severe harm. The emotional reactions in question are responses to that harm. It is because 'marginal' humans have undergone such harm that there is a morally significant disanalogy between them and non-humans.

I conclude then, that the tragedy that marginal humans have suffered is a consideration sufficient to support a preference for such humans over animals of equivalent capabilities in situations where one or the other must be used for research. For example, if painful biomedical research were necessitated by the outbreak of a virulent epidemic - consider, for example, an AIDS-type malady that was spread readily through casual contact - it would not be arbitrary species prejudice to experiment upon animals rather than 'marginal' humans. To choose human subjects would exhibit a lack of sensitivity to the harm suffered by the humans, but not by the non-humans.

But this distinction between animals and humans does not entail the view that animals, unlike marginal humans, lack such moral prerogatives as the right to continued existence, or the right to freedom from undeserved, non-trivial suffering. Nor does it imply that all marginal humans have these rights. For although the deprivation suffered by marginal humans, and not by animals, undergirds our sense of the humans' tragedy, the moral status that people (in general) are inclined to attribute to both kinds of creature cannot be plausibly understood as entirely due to those deprivations. Properties that creatures actually possess (such as sentience, or Tom Regan's notion of being the 'subject of a life' and hence the centre of experiences whose quality may be better or worse from a being's own point of view) (8) remain

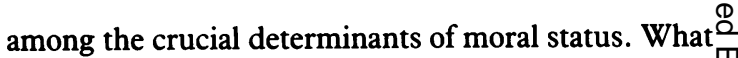
it means to treat marginal humans and non-humans $\underset{\vec{F}}{\vec{F}}$ with due respect will be greatly influenced by which properties they in fact have, as well as which properties:they might have had.

\section{Acknowledgements}

Versions of this essay have been read at meetings of the Canadian Philosophical Association and American $\overparen{\otimes}$ Philosophical Association. I am grateful for the close of attention of my commentators, Professors Brian Keenan and Edward Sankowski, as well as to the members of the Central Minnesota Philosophy Group, $\vec{\omega}$ especially Hilde Lindemann Nelson.

fames Lindemann Nelson is Associate Professor of: Philosophy at St Fohn's University in Collegeville, $\overrightarrow{+}$ Minnesota, and has taught in the Medical School at the $e_{-}^{+}$ University of Minnesota. He is currently engaged in a $\overrightarrow{0}$ research project on the use of animal models in medical research, funded by the National Science Foundation and 5 the National Institutes of Health.

\section{References}

(1) Frey R G. Vivisection, morals, and medicine. Fournal of $\frac{\bar{B}}{\sigma}$ medical ethics 1983; 9: 93. For a closely related discussion $₫$ see Frey R G. Rights, killing and suffering. Oxford: BasilBlackwell, 1983.

(2) See, for representative arguments: Benson J. Duty amd the beast. Philosophy 1978; 58: 529-549; Francis LP. Norman R. Some animals are more equal than othes Philosophy 1978; 58: 507-527; and Frey R G. AnimaP rights. Analysis 1977; 37: 186-189.

(3) Regan T. An analysis and defense of one argumen concerning animal rights. Inquiry 1979; 22: 189-219.

(4) Nagel T. Death. Nous 1970; 4: 73-80.

(5) See, for example, Kripke S. Naming and necessity Cambridge: Harvard University Press, 1980.

(6) Even if natural laws do express metaphysical necessities the causal relationships described by those laws can be altered by altering variables. For example, prenatal op postnatal therapies might supplement whatever defects if phenotypic structures which are necessary consequences? of the genotype.

(7) Some readers have wondered whether this position implies that a severely abnormal non-human animak should be accorded experimental immunity over a healthp conspecific; such a consequence seems counterintuitive But the appropriate analogy is not to a defective versus healthy collie pup; rather, the defective animal should be compared with an animal of another species whose normass complement of life-enriching properties is equivalent to that actually possessed by the defective animal. The morat consequences of such a comparison are too complex to be discussed here, but they promise to be less intuitivelf unsettling than being compelled to champion the defective collie over the healthy one. In any evento insisting on the moral significance of the harm suffered if? being a 'marginal case' (whether of a human or a dog) needo not blind one to other features of moral importance.

(8) Regan T. The case for animal rights. Berkeley and Lo Angeles: The University of California Press, 1983. 